\title{
NONCOOPERATIVE SUPPORT OF PUBLIC NORM ENFORCEMENT IN LARGE SOCIETIES
}

\author{
JOSEF FALKINGER
}

\section{CESIFo Working PAPER No. 1368 \\ CATEGORY 1: PUBliC FinANCE \\ DECEMBER 2004}

Presented at the CESifo Area Conference on Public Sector ECONOMics, MAY 2004

\footnotetext{
An electronic version of the paper may be downloaded

- from the SSRN website: http://SSRN.com/=646021

- from the CESifo website: www. CESifo.de
} 


\title{
NONCOOPERATIVE SUPPORT OF PUBLIC NORM ENFORCEMENT IN LARGE SOCIETIES
}

\begin{abstract}
In small groups norm enforcement is provided by mutual punishment and reward. In large societies we have enforcement institutions. This paper shows how such institutions can emerge as a decentralized equilibrium. In a first stage, individuals invest in a public enforcement technology. This technology generates a sanctioning system whose effectiveness depends on the aggregate amount of invested resources. In a second stage, in which individuals contribute to the provision of a public good, the sanctioning system imposes penalties and rewards on deviations from the endogenous norm contribution. It is shown that even if group size goes to infinity public norm enforcement is supported in a noncooperative equilibrium. Psychological factors are not necessary but can be favorable for the emergence of effective public norm enforcement.
\end{abstract}

JEL Code: H41, K40, Z13.

Keywords: norm enforcement, public goods, institutions, sanctioning.

\author{
Josef Falkinger \\ University of Zurich \\ Socioeconomic Institute \\ Zürichbergstr. 14 \\ 8032 Zurich \\ Switzerland \\ josef.falkinger@wwi.unizh.ch
}

I wish to thank Ernst Fehr, Simon Gächter, Volker Grossmann, Michael Kosfeld and the participants of the CESifo workshop in Public Economics at Munich, in particular Armin Falk and Richard Cornes, for very valuable discussions and comments. 


\section{Introduction}

Sociologists point out that people behave in accordance with norms. Economists tend to emphasize that individuals act according to their interests. This paper provides an economic explanation of why self-interested individuals voluntarily support the public enforcement of norms even though this enforcement forces them to comply with a norm they would violate without public enforcement. The emphasis is on large economies with arbitrarily many individuals.

Interests in a norm arise when "an action has similar externalities for a set of others" (Coleman [1990], p. 251), in particular in the case of providing a public good. Therefore, the relationship between individual interests and norm enforcement is studied in a model of public good provision. In the standard public good model, in which utility is a function of private consumption and total supply of the public good, individuals are free-riding on the contributions of others. As a result, we have underprovision of the public good in a noncooperative equilibrium. Experimental economics has shown that free-riding behavior is less pervasive than economic theory suggests. Nonetheless, it is an undisputed fact that less than an efficient level of a pure public good is supplied when its provision is left to voluntary contributions (see Ledyard [1995] for a survey). The question to which extent free-riding behavior destroys public good provision is of particular interest when public goods concerning large populations are involved. According to the traditional economic view, the willingness to contribute to a public good shrinks if group size increases and tends to vanish if population size grows toward infinity (Andreoni [1988]). Experimental research does not support such a size effect for the provision of a pure public good in groups up to 100 members (Isaac and Walker [1988], Isaac, Walker and Williams [1994]). Also field evidence on donations to charities challenges the traditional model of noncooperative public good provision (Andreoni [1988]). There are two main strategies for reconciling theory with these facts. Either we change individual preferences to include extra motives of contributing to the public cause, or we account for norm enforcing, assuming standard individual preferences. The inefficiency resulting from free-riding explains why there is a 
demand for a norm that tells individuals how much they should contribute. However, a norm is only effective if there are means to enforce it by sanctions and rewards. Since means of enforcement are costly for the agents who provide them, while the benefits of induced norm compliance accrue to everybody, we have again a free-rider problem. How can this "second-order public good" problem be solved in an economic approach based on decentralized equilibrium outcomes of free individual behavior?

Behavioral economics has provided insights on how cooperation in groups can be sustained by altruistic punishment and altruistic rewarding (Fehr and Gächter [2000, 2002], Fehr and Fischbacher [2003]). This type of enforcement requires some social relationship between agents which may not be realistic at the level of a large anonymous society. ${ }^{1}$ If social conditions like neighborhood and personal communication are not met, especially in large associations, effective norm enforcement must be more formal and explicit. Typically we observe delegation to an institution with officials and staff employed for looking that all members contribute their share to public goods. ${ }^{2}$ I use the term "public norm enforcement" to address this phenomenon. ${ }^{3}$ We have it not only in associations like states with police and tax administration, but also in communes, trade unions, professional associations or churches.

For explaining public norm enforcement as outcome of decentralized decision making of free and rational individuals we have to answer two questions: How is the norm contri-

\footnotetext{
${ }^{1}$ Yamagishi [1986] proposed to distinguish "elementary cooperation" and "instrumental cooperation". Since in large groups it is not possible to guarantee elementary cooperation by mutual control, people cooperate at an instrumental level by establishing a sanctioning-system. He supports this idea by experimental evidence.

${ }^{2}$ Huck and Kosfeld [2004] consider an interesting "hybrid" mechanism. There is a central punishment institution (the state) but the central authority can only act if individuals report deviant behavior in their neighborhood. Public rules and private engagement in social control interact in this model.

${ }^{3}$ Carpenter [2004] showed in recent experiments that it is indeed the limited capacity of individuals to personally monitor others which makes mutual monitoring less effective in larger groups. This suggests that in large associations public enforcement with professional staff may be the superior institution for supporting cooperation.
} 
bution to the public good defined? And, are individuals willing to contribute sufficiently to the financing of a norm-enforcing agency to give the agency the economic means for implementing the norm effectively? Formally, these questions are analyzed in a two-stage game, where at Stage 1 agents can contribute to public norm enforcement and at Stage 2 they can contribute to a public good that generates intrinsic value, for example, public security or environmental quality. I call the public good provided at Stage 2 "intrinsic" public good if distinction from the public good "norm enforcement" is necessary. Contributions to a public good are modelled as strategies in a non-cooperative game (Bergstrom, Blume and Varian [1986], Cornes and Sandler [1986]). At this point it is important to note the positive character of the presented analysis. The purpose of this paper is not to present a two-stage game which implements efficient public good provision. The literature on mechanism design has shown that this is possible in principle and concrete designs have been proposed (e.g. Varian $[1994 \mathrm{a}, \mathrm{b}]$ ). Here, the goal is to provide an economic explanation for a typical institutional feature of economies - public norm enforcement.

For isolating the second-order public good problem "norm enforcement" in a clean way I adopt the following methodological strategy. First, without public norm enforcement the intrinsic public good is supplied at an inefficiently low level due to free-riding. In particular, per-capita contribution decreases and eventually vanishes if population size increases. This captures the idea that norm enforcement is essential. ${ }^{4}$ Secondly, an effective enforcement technology exists. That means, it is possible to induce also in large groups substantial individual contributions to the intrinsic public good if a sufficient amount of economic resources is invested into the enforcement technology. The amount which would be invested by a planner who is not constrained by the second-order free-rider problem defines the benchmark to which the noncooperative equilibrium is to be compared. This approach is analogous to the comparison of market solution and central coordination in general equilibrium analysis. Just as a decentralized market economy is not a tabula rasa

\footnotetext{
${ }^{4}$ Even in the case of tax-financed public provision of a public good, sanctioning systems are required to induce compliance with the tax law - due to asymmetric information.
} 
at which individuals with given endowments and preferences interact without production possibilities, noncooperative public norm enforcement does not mean that no technological means of control or no psychological Know-how to influence individual behavior are available. The question is rather how much resources are supplied to use the means and the Know-how. Noncooperative support of public enforcement means that individuals without coordination or coercion by a central authority invest a sufficient amount to produce effective public enforcement.

More specifically, agents are endowed with an economic resource and have preferences over private consumption and a pure public good (the first-order or intrinsic public good). At Stage 1, they individually decide how much of their endowment they contribute to a public enforcement funds. ${ }^{5}$ In a second stage, the individuals decide how much they contribute to the (intrinsic) public good. This contribution game at Stage 2 is subject to public norm enforcement. Sanctions are imposed on agents contributing less than a norm, and rewards are given to those who contribute more. The larger the enforcement funds provided at Stage 1 the more powerful are the sanctions and rewards. Finally, the idea of a decentralized equilibrium requires that also the norm is endogenously generated by individual behavior. This is achieved by making the norm a function of average contribution. We know that punishing and rewarding deviations from average can induce efficient contribution levels if there is no second-order public good problem (see Falkinger [1996] for a theoretical proof and Falkinger, Fehr, Gächter and Winter-Ebmer [2000] for behavioral evidence in laboratory experiments). ${ }^{6}$ In the framework considered here, this Know-how is part of the given technology. To make it effective, resources must be invested. There is no exogenous authority deciding about the degree of effective enforcement. The power of the sanctions and rewards imposed on the individuals at Stage 2 is endogenously determined by the individuals' contributions to the public enforcement funds at Stage 1. In the two-stage equilibrium, both the individual contributions to public norm enforcement and the contributions to the intrinsic public good induced by public norm enforcement

\footnotetext{
${ }^{5}$ This corresponds to Yamagishi's [1986] experimental design for testing "instrumental corporation". ${ }^{6}$ See Chen [forthcoming] for stability and learning properties.
} 
are determined for a given set of players. Given the fact that the problem of defection and public norm enforcement is of particular relevance in large anonymous societies, a central question will be how the equilibrium behaves if the number of players is large, i.e. goes to infinity. We will see that, unlike contributions to the intrinsic public good without enforcement, the contributions to public enforcement do not vanish.

The paper is organized as follows. Section 2 discusses related work on organizations and institutions. Section 3 outlines the basic model. Section 4 considers the case that public enforcement is a pure public good with no rivalry in utilization. The theoretical results are illustrated by numerical simulations. In Section 5 the case of full rivalry is analyzed, that is, per-capita contribution determines the degree of enforcement. Section 6 discusses the interaction between economic support of norm enforcement and psychological factors. Section 7 summarizes the results.

\section{Related Literature}

The problem of individual support of public norm enforcement is closely related to the more general question of how formal organizations and institutions can be explained in an economic approach based on autonomous self-interested individuals. As Olson [1965] pointed out, an important characteristic of organizations is "the furtherance of interests of their members", that is, the provision of some public good. And "just as a state cannot support itself by voluntary contributions ... neither can other large organizations support themselves without providing some sanctions ... that will lead individuals to help bear the burdens of maintaining the organization" (p. 15). This leaves us again with the question why at some stage individuals give to an institution sufficient economic means to provide the second-order public good sanctioning and enforcement of behavior in favor of the institution.

Following John Locke, the theory of social contracts has argued that "rational individuals, each possessing natural rights, will engage in a joint social contract to give up 
to a central authority those rights which if held and exercised centrally will make them better off" (Coleman [1990], p. 328). Such an approach focusses on the legitimacy of a central authority, as opposed to anarchy or dictatorial usurpation. The economic approach presented in this paper does not start with a virtual state of nature. Object of the analysis is an economy in some given moment in time, characterized by the usual fundamentals: Preferences, endowments and production possibilities. Production possibilities include the technology by means of which endowments can be transformed into the production of sanctions and rewards. This technology may be as simple as paid agents going around, watch people's behavior and react to them according to steps written down in a manual. At more advanced levels of economic development, more sophisticated enforcement technologies are feasible. Automatic surveillance devices, refined statistical methods for random control, well-targeted instruments of hindering or promoting norm-relevant activities, psychologically more effective ways of sanctioning, media channels to report disapproval of unwanted and praise of wanted behavior to a wider audience, or the like. Just as technical progress raises productivity in the production of private goods, innovations in the feasible means of control and sanctioning change the possibilities of norm enforcement. Also, just as with private production technologies, feasibility of a public enforcement technology does not mean that it is actually used. Generating output requires employment of input. In the context of norm enforcement: Depending on how much resources the individuals contribute to the funds invested into the enforcement technology, the realized sanction-reward structure exerts more or less pressure toward norm compliance. Thus, the analysis explains the effective means - the resources - given to public enforcement. Since by assumption the means are given voluntarily by free and rational agents, legitimacy is not an issue. The problem is efficiency, in particular, whether or not support of public norm enforcement breaks down if the number of individuals gets large and no personal relationship controls free-riding. ${ }^{7}$

\footnotetext{
${ }^{7}$ Whereas the normative approach of social contract theory addresses the legitimacy of institutions by asking which contract individuals would sign, this positive analysis asks how much resources individuals contribute to first- and second-level public goods in a noncooperative equilibrium. However, I don’t claim
} 
The analysis is related to Okada's [1993, 1997] noncooperative approach to social organizations. ${ }^{8}$ Like in Okada's work, social organizations (institutions) have the purpose of inducing behavior that is favorable for the common benefit by giving to a professional enforcement agency the economic means to sanction free-riding. However, my goal is to explain the emergence of enforcement institutions without involving collective decision making (like voting or bargaining) at any stage. Moreover, I am not interested in the formation of small social organizations like clubs but in an explanation of why enforcement institutions covering large populations find support without assuming any preexisting central authority. There is no constitutional rule stipulating how collective decisions are made and there is no stage at which individuals "sign a social contract", i.e. decide whether to enter into the social organization. Instead, there is an enforcement technology in which individuals can invest. The enforcement produced by the aggregate amount of individual contributions is applied to everybody regardless of an individual's support of enforcement by own investments. I think this public character is an important feature of social norms and their enforcement in territorially rooted populations. More generally, whenever a norm is backed by an enforcement institution with sufficient economic resources, an individual member of a population cannot simply escape. ${ }^{9}$ Consequently, the size of the considered social organization is identical to an exogenously given population. It should be noticed that feasibility of an enforcement technology does not require a central authority but equipment and Know-how. Take for instance a global public good like environmental quality. Inspection and information technologies, but also economic to provide an explanation of how enforcement institutions evolve over time like evolutionary approaches to the social contract (Skyrms [1996]) or to social norms (Sethi and Somanathan [1996]).

${ }^{8}$ See Kosfeld and Riedl [1994] for a discussion of experimental evidence on decentralized individual punishment in comparison to the formation of a centralized sanctioning institution in Okada's theoretical set up: Individuals can decide about participating in a club (participation stage) whose members vote or bargain on whether to implement a punishment institution (negotiation stage) which enforces public good provision among club members (contribution stage). Non members free-ride on the club.

${ }^{9}$ Not only fleeing may be impossible - which in the case of global enforcement definitely is. Also psychological cost of nonconformity may be high (Bernheim [1994]). 
Know-how about intelligent incentive systems exist. Instead of considering negotiations, contracts or international constitutions, the approach in this paper is: Suppose an entrepreneurial agent invites people to spend money into a funds and uses the raised money for employing existing control technologies and incentive mechanisms to induce behavior that is beneficial for environment quality. The question is to which extent people follow the invitation and contribute to the funds. Is it possible to enforce a certain behavior in this way (rather than by negotiation or consensual agreements)? The problem is that the enforcement funds are invested into the production of a public good. The good - norm enforcement - may be rival or not, as discussed later. In any case, it is public insofar as nobody is excluded from its effects. The challenge is to show that effective public norm enforcement can be supported by a noncooperative equilibrium even if the population is very large and very strong free-riding incentives work against the provision of goods for the public benefit.

\section{Basic model}

The economy consists of $n$ individuals with preferences over private consumption $c$ and a public good $G$, represented by the utility function

$$
U(c, G)=c^{\alpha} G^{1-\alpha} .
$$

(The purpose of this section is to present the argument in the most simple form. The CobbDouglas function allows explicit solutions. Appendix A outlines the model for general utility functions.)

Each individual is endowed with gross income $y_{i}, i=1, \ldots, n$. Public good $G$ is supplied at Stage 2 by private contributions, i.e. $G=\sum_{i=1}^{n} g_{i}=g_{i}+G_{-i}$, where $g_{i}$ is individual $i^{\prime}$ s contribution and $G_{-i} \equiv \Sigma_{j \neq i} g_{i}$.

At Stage 1 individuals have the possibility to contribute some amount $e_{i} \geq 0$ to a

public enforcement funds. This funds is invested into a norm-enforcing technology $\widetilde{f}$ 
employed at Stage 2. An aggregate amount $E=\Sigma_{i=1}^{n} e_{i}=e_{i}+E_{-i}, E_{-i} \equiv \Sigma_{j \neq i} e_{j}$, of public enforcement resources produces a sanctioning strength $\widetilde{f}(E, n)$ which allows to effectively impose the punishment-reward scheme

$$
r_{i}=\tilde{f}(E, n)\left(g_{i}-\bar{g}_{-i}\right)
$$

on the individuals' contribution behavior at Stage $2 .{ }^{10}\left(r_{i}\right.$ is measured in units of endowments.)

The norm to which an individual's contribution $g_{i}$ is compared is the average amount $\bar{g}_{-i} \equiv \frac{G_{-i}}{n-1}$ of the contributions of all others. Thus, the norm is endogenously formed by the population. There is no social planner defining the norm. Norm compliance induced by internalized controls would mean that deviations from the norm are penalized or rewarded by an exogenous rate $\beta_{0}$ requiring no economic resources. ${ }^{11}$ Delegation of enforcement to an agency means that the effective penalty-reward strength is produced by employing resources $E$ into a technology $\tilde{f}$. This technology consists of two components

$$
\widetilde{f}(E, n)=\beta f(E, n)
$$

where $f(0, n)=0, f(E, n) \leq \bar{f}, f_{E}>0$ and $f_{E E}<0$ is assumed. (Subscript notation is used for partial derivatives.) $\beta$ is the nominal strength of the means allowed to induce norm compliance. Incentive researchers may recommend a certain size of $\beta$ and write it into the instructions for $\tilde{f}$. This requires neither authority nor resources - only expertise. However, without employing resources, $\beta$ is just a number, a parameter that can be set. (In Section 4 the parameter is fixed to $\beta=1$. In Section 5 the role of adjustments of $\beta$ is considered.) The effective sanctioning strength is $\beta f$. It depends on the degree of enforcement, that is, on the economic resources applied to produce an effective degree of enforcement $f$. More resources allow a higher degree $\left(f_{E}>0\right)$. For instance, larger funds

\footnotetext{
${ }^{10}$ Second-order punishing (rewarding) would mean that $\tilde{f}$ is employed also at Stage 1 . In principle, one may have many stages with third-order enforcement and so on. In the end, the important distinction is between situations with enforcement and without.

${ }^{11}$ The role of psychological controls will be discussed in Section 6 .
} 
allow more freqent inspection and more effective monitoring of contribution behavior at Stage 2. If individuals decide to contribute zero to $E$, effective sanctioning strength $\tilde{f}$ is zero whatever is the size of the nominal strength $(\beta) .{ }^{12}$ The marginal productivity of increasing enforcement resources diminishes $\left(f_{E E}<0\right)$ and the degree of enforcement is limited by some upper bound $(f \leq \bar{f})$. Population size $n$ should not matter if public enforcement is a pure public good characterized by non-rivalry. This is assumed in the enforcement technology considered in the next section. Section 5 considers a technology with full rivalry, which means enforcement is a public good only in the sense of nonexcludability. Apart from $E$, there are no public cost of imposing scheme (3), since $\sum_{i=1}^{n} r_{i}=0 .{ }^{13}$ The next subsection characterizes Stage 2 for a given size of enforcement funds $E .^{14}$

\subsection{Stage 2 equilibrium}

At Stage 2, the budget constraint of an individual $i$ is given by the equation

$$
\begin{aligned}
c_{i} & =y_{i}-e_{i}-g_{i}+r_{i} \\
& =y_{i}-e_{i}-(1-\beta f) g_{i}-\beta f \bar{g}_{-i}
\end{aligned}
$$

where $e_{i}$ was spent at Stage 1 and $r_{i}$ results from penalty-reward scheme (2) imposed by enforcement technology (3). For notational simplicity the arguments of $f$ are suppressed.

Maximizing (1) subject to (4), individual $i$ chooses $g_{i}$ so that

$$
M R S=1-\beta f
$$

where $M R S \equiv \frac{1-\alpha}{\alpha} \frac{c_{i}}{G}$ is the marginal rate of substitution between private consumption $c_{i}$ and public good $G$. The right-hand side of equation (5) is $i$ 's effective marginal cost (the

\footnotetext{
${ }^{12} f(0, n)>0$ would mean that an exogenous ("psychological") penalty-reward mechanism is effective without investing any economic resources.

${ }^{13}$ Use $\sum_{i=1}^{n} G_{-i}=(n-1) \sum_{i=1}^{n} g_{i}$ and thus $\sum_{i=1}^{n} \bar{g}_{-i}=\sum_{i=1}^{n} g_{i}$.

${ }^{14}$ Stage 2 game is a special instant of Falkinger [1996] where general utility functions are considered and uniqueness as well as efficiency of equilibria are discussed.
} 
"price" in terms of private consumption) of contributing to the public good. A higher degree of enforcement reduces this cost, since an increase of $g_{i}$ reduces punishment (as long as $g_{i}<\bar{g}_{-i}$ ) or increases rewards (if $g_{i}>\bar{g}_{-i}$ ). At the same time, a lump-sum tax $\beta f \bar{g}_{-i}$ is imposed on $i$ 's budget (4). ${ }^{15}$

In a meaningful economic model the effective price of contributing to the public good, $1-\beta f$, must be positive. Thus, we impose the restriction $\beta \bar{f}<1$ on the enforcement technology. ${ }^{16}$

Summing (4) over all $i$, we obtain the following restriction on aggregates:

$$
G=Y-E-C
$$

with $Y \equiv \sum_{i=1}^{n} y_{i}, C \equiv \sum_{i=1}^{n} c_{i}$.

Thus, condition (5) can be rewritten in the form

$$
c_{i}=(Y-E-C) \rho, \quad \rho(E, n) \equiv \frac{\alpha}{1-\alpha}(1-\beta f(E, n)) .
$$

(Again the arguments of $\rho$ are suppressed to save notation.)

Aggregating this equation and solving for $C$, we obtain

$$
C=\frac{\rho n}{1+\rho n}(Y-E)
$$

\footnotetext{
${ }^{15}$ Effective enforcement strength $\beta f$ works like government subsidies for private donations to public goods. Roberts [1987, 1992], Boadway, Pestieau, and Wildasin [1989], among others, have analyzed such subsidies under the assumption that individuals do not anticipate the taxes by which the subsidies are financed. In contrast, reward structure $(2)$ is self-financing $\left(\sum r_{i}=0\right)$ and individuals account for the implied tax burden $\beta f \bar{g}_{-i}$. See Andreoni and Bergstrom [1996] for another model in which subjects account for the government's budget constraint. Brunner and Falkinger [1999] provide a general characterization of the effects of taxes and subsidies in an economy with private provision of public goods.

${ }^{16}$ This can also be interpreted as follows: An increase in the effective sanctioning strength is not necessarily beneficial, since it may induce overcontribution to the public good. With very steep sanctions, individuals would give all their endowment for $G$.
} 
and, according to $(6)$,

$$
G=\frac{Y-E}{1+\rho n}
$$

Without effective sanctioning, i.e. if $E=0$ and $\beta f=0$, we have $\rho=\frac{\alpha}{1-\alpha}$ and percapita contribution to public good $G$ is $g^{0}(n)=\frac{y}{1+\frac{\alpha n}{1-\alpha}}$ in a noncooperative equilibrium. $g^{0}(n)$ vanishes if $n$ is getting large. Thus, the model reflects the familiar conjecture that free-riding destroys voluntary public good supply in large populations when individuals have standard preferences and no institution enforces norm compliance. The question is whether the problem is overcome if individuals can invest in public enforcement funds.

Finally, after substitution of (8) for $C$ in equation (7) and substitution of (7) and (9) for $c_{i}, G$ in utility function (1), the pay-off that can be achieved by an agent at Stage 2 is given by the indirect utility function

$$
V(E)=\frac{\rho^{\alpha}}{1+\rho n}(Y-E)
$$

(Note that $\rho=\frac{\alpha}{1-\alpha}[1-\beta f(E, n)]$ depends on the contributions to enforcement funds $E$.) Since $c_{i}>0$ and $G>0$, according to first-order condition (5), $E<Y$ and thus $V>0$.

\subsection{Stage 1 equilibrium}

At Stage 1, individual $i$ 's decision problem is

$$
\max _{e_{i}} V\left(e_{i}+E_{-i}\right)
$$

Differentiation of (10) gives us, after rearranging terms ${ }^{17}$,

$$
V^{\prime}=\left[\left(\frac{\alpha}{\rho}-\frac{n}{1+\rho n}\right) \rho_{E}-\frac{1}{Y-E}\right] V,
$$

where $\rho_{E}=-\beta f_{E}$.

\footnotetext{
${ }^{17}$ According to $(10), V^{\prime}=\frac{\alpha \rho^{\alpha-1}(1+\rho n)-\rho^{\alpha} n}{(1+\rho n)^{2}} \rho_{E}(Y-E)-\frac{\rho^{\alpha}}{1+\rho N}$. Dividing by $V$, we get $\frac{V^{\prime}}{V}=$ $\frac{\frac{\alpha}{\rho}(1+\rho n)-n}{1+\rho n} \rho_{E}-\frac{1}{Y-E}$ which gives (12). Note that $c_{i}>0, G>0$ imply $E<Y$ and thus $V>0$.
} 
Since $V>0$, the first-order condition for problem (11) is given by the equation

$$
F(E, n) \equiv\left(\frac{\alpha}{\rho}-\frac{n}{1+\rho n}\right) \rho_{E}-\frac{1}{Y-E}=0 .
$$

Provided that the second-order condition holds ${ }^{18}$, equation (13) uniquely characterizes the equilibrium size of the public enforcement funds $E^{*}$. Since $e_{i}$ and $E_{-i}$ substitute each other one to one, the Nash equilibrium supporting $E^{*}$ is not unique. Note however that with $E^{*}$ also $C$ and $c_{i}$ are unique according to (7) and (8). Thus, only the distribution of an individual's contributions to the public cause, on $G$ or $E$, is undetermined.

Note also that without sanctioning, i.e. if $\beta=0$, we have $\rho_{E}=0$ and thus $E^{*}=0$, since $F<0$ in this case. Obviously, contributing to a public enforcement funds would be useless if it is not used to exert pressure for norm compliance at Stage 2. Finally, at an equilibrium $E^{*}>0$ defined by condition (13), utility $V\left(E^{*}\right)$ achieved in the equilibrium is higher than utility without enforcement $V(0) .{ }^{19}$ Thus, although norm enforcement has costs (the higher $E$, the lower is the income $Y-E$ remaining for public good $G$ and private consumption $C$ ), incurring these costs up to equilibrium amount $E^{*}$ is welfare improving.

The next section characterizes the equilibrium for the case that public enforcement is a pure public good.

\section{Noncooperative equilibrium with non-rival public enforcement}

In general, the degree of enforcement $f$ depends on both the volume of available enforcement resources $E$ and the number of individuals $n$ whose norm compliance has to

\footnotetext{
${ }^{18}$ The second-order condition $V^{\prime \prime}=V^{\prime} F+V F^{\prime}<0$ is satisfied at $V^{\prime}=0$ if $F^{\prime}<0$. A sufficient condition for this inequality is given in Appendix B. The condition holds for all enforcement systems considered in the further analysis.

${ }^{19} V^{\prime}\left(E^{*}\right)=0$ and $V^{\prime \prime}(E)<0$ at any $E$ with $V^{\prime}(E)=0$ imply that $E^{*}$ is a global maximum of $V$ with $V^{\prime}(E)>0$ for $E<E^{*}$.
} 
be controlled. If public enforcement is a pure public good without any rivalry in use, population size $n$ plays no role. For instance, enforcement may require to set up some monitoring device which is subject to economies of scale. The efectiveness of the device varies, depending on how much resources are spent on it, but given the total amount of spent resources, the number of monitored individuals is unimportant. Let the degree of enforcement be given by ${ }^{20}$

$$
f(E, n)=1-\frac{1}{1+E}
$$

With (14) the degree of enforcement is strictly concave in $E$, increasing from zero for $E=0$ to one as $E$ grows to infinity. Thus, $f$ satisfies the properties required in Section 3.

Normalizing the maximal strength of sanctions (imposed under perfect enforcement when enforcement degree $f$ is equal to 1 ) to $\beta=1$, we get for the effective price of contributing to the public good $1-\beta f=\frac{1}{1+E}$ and thus

$$
\rho=\frac{\alpha}{1-\alpha} \frac{1}{1+E}
$$

With this specification first-order condition (13) reduces to the following quadratic equation in per-capita contribution $e \equiv E / N$ to the public enforcement funds: ${ }^{21}$

$$
D(n)-k(n) e=(1-\alpha) e^{2}
$$

\footnotetext{
${ }^{20}$ As can be seen from the proofs in the appendix, the results go through if $f(E, n)=1-\frac{B}{1+E}, 0<$ $B \leq 1$, is considered instead of (14). $B<1$ means that even without enforcement resources the degree of enforcing sanctions and rewards is positive, namely $f(0, n)=1-B$. Thus, non-economic factors are dampening free-riding. The only important effect of $B<1$ is that the group size for which substantial contributions to the public good can be expected without public enforcement increases. In Section 5, a more flexible functional form with three parameters $\gamma, A$ and $B$ is used, where $\gamma$ represents the degree of rivalry (equal to zero in this section) and $A, B$ are efficiency parameters. The role of $A, B$ is discussed in Section 6.

${ }^{21}$ Set $\gamma=0$ and $B=1$ in Appendix C. For the proof that the second-order condition for a maximum holds at $e$ determined by (16) see Appendix B.
} 
with $D(n) \equiv \alpha y-\frac{\alpha}{n}\left(y+\frac{1}{1-\alpha}\right)-\frac{1}{n^{2}}$ and $k(n) \equiv \frac{2-\alpha}{1-\alpha} \alpha+\alpha y+\frac{2-\alpha}{n}$, where $y \equiv Y / n$ denotes per-capita income.

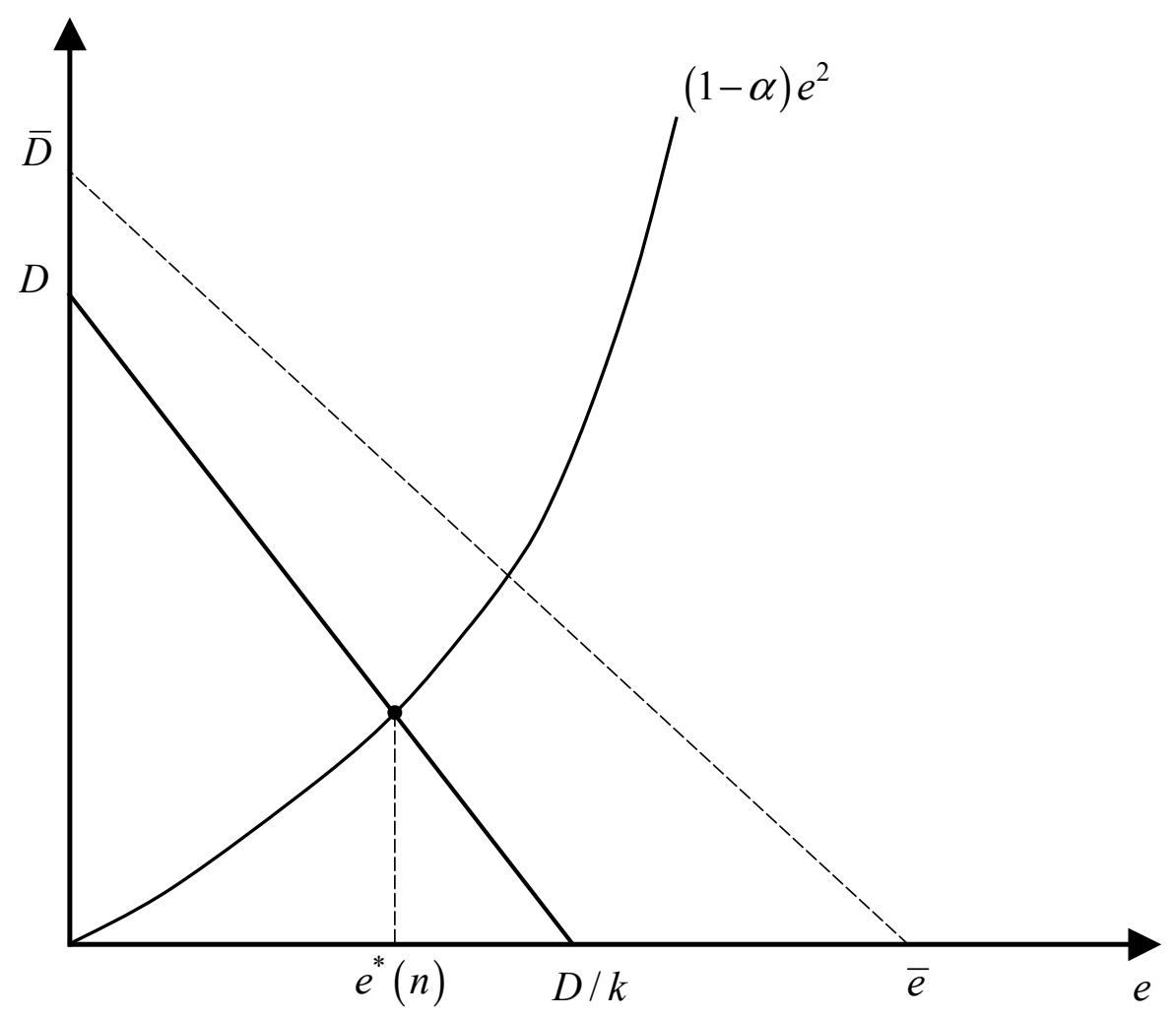

Figure 1: Equilibrium contribution to non-rival public enforcement

$D(n)$ is an increasing function of $n$, reaching $D\left(n_{0}\right)=0$ at $n_{0}>1$ and approaching $\bar{D} \equiv \alpha y$ as $n$ goes to infinity, whereas $k(n)$ decreases with $n$ eventually going to $\bar{k} \equiv$ $\frac{2-\alpha}{1-\alpha} \alpha+\alpha y>0$. Thus, for $n>n_{0}$ equation (16) defines a unique contribution level $e^{*}(n) \in(0, D(n) / k(n))$ where $D(n) / k(n)$ increases with $n$ towards $\bar{e} \equiv \bar{D} / \bar{k} \cdot{ }^{22}$ For ${ }^{22}$ Note that $\bar{D} / \bar{k}<\min \{1, y\}$. 
$n \leq n_{0}$, we have $e^{*}(n)=0$. Figure 1 illustrates this solution of (16). (The negatively sloped line representing the left side of (16) approaches the dashed line as $n$ increases to infinity.)

$e^{*}(n)$ is the per-capita contribution to the public enforcement funds resulting in Stage 1 equilibrium. Since $D(n)$ increases whereas $k(n)$ decreases, $e^{*}(n)$ is an increasing function of $n$. The following proposition summarizes this result.

Proposition 1 . Public norm enforcement in large societies can indeed result as noncooperative outcome of voluntary contributions of selfish individuals. Above some minimum group size, $n>n_{0}$, equilibrium per-capita contribution to the public enforcement funds invested in technology (14) is given by an increasing function $e^{*}(n) \in(0, y)$ of population size $n$.

This shows that free-riding in supplying the second-order public good "enforcement" is less a problem in large societies than it may be in small groups. ${ }^{23}$ Provided that innovations have brought about the technical possibility of public norm enforcement, economic resources for employing this possibility are voluntarily contributed even by purely selfish individuals. The reason is, individuals anticipate that by contributing to the public enforcement funds they can exert pressure on the others to contribute to the intrinsic public good in the second stage. Thus, besides the positive external effect of an individual's contribution to the public good $E$ at Stage 1, the contribution at Stage 1 has a negative external effect on others at Stage 2. In small groups $\left(n \leq n_{0}\right)$ this does not give sufficient motives for selfish individuals to contribute to public sanctioning and rewarding. So some kind of alternative motives like altruistic punishment is required to explain why punishing and rewarding of deviators occurs also in small groups. In large anonymous societies such reliance on altruistic behavior seems less convincing. Nor is it necessary as the presented analysis shows.

\footnotetext{
${ }^{23}$ Threshold $n_{0}$ which must be passed to yield $e^{*}(n)>0$ is defined by $D\left(n_{0}\right)=0$. Since $D(n)$ increases in both $n$ and $y$, the threshold is lowered if $y$ rises.
} 
In the presented framework, enforcement as such does not generate utility. ${ }^{24}$ It has only indirect value through the provision of $G$. Ultimately, the relevant question is which level of public good $G$ is provided under $e^{*}$. Again we focus on the per-capita level $g \equiv \frac{G}{n}$. Substituting (15) for $\rho$ in equation (9) and dividing by $n$, we get

$$
g^{*}(n)=\frac{y-e^{*}(n)}{1+\frac{\alpha}{1-\alpha} \frac{1}{1 / n+e^{*}(n)}} .
$$

Since $e^{*}<\bar{e}<y$, we have $g^{*}>0$. Population size $n$ has a direct negative effect on $g^{*}$. This is the usual effect that free-riding increases if group size increases. However, as we have seen an increase in $n$ increases $e^{*}$. Thus, there is also an indirect effect of $n$ on $g^{*}$ through stronger norm enforcement. And this effect is positive. ${ }^{25}$ The numerical simulations presented below illustrate the net impact of the negative direct and the positive indirect effect of population size on $g^{*}$. But the central conclusion can be drawn generally: Even in very large societies, the private provision of public good $G$ does not break down. According to (17), with $n$ going to infinity $g^{*}$ approaches $g_{\infty}=\frac{y-e_{\infty}}{e_{\infty}+\frac{\alpha}{1-\alpha}} e_{\infty}>0$, where $e_{\infty} \equiv \lim _{n \rightarrow \infty} e^{*}(n)$ and $0<e_{\infty}<y$ according to Proposition 1. Without enforcement ${ }^{26}$, i.e. with $e=0$, we would have $g=\frac{y}{1+\frac{\alpha}{1+\alpha} n}$ which vanishes if $n$ goes to infinity. Only the fact that subjects contribute to public norm enforcement at Stage 1 guarantees that private contributions to the public good at Stage 2 do not vanish despite selfishness and infinitely large population size. This establishes our second result.

\footnotetext{
${ }^{24}$ de Quervain, Fischbacher et al. [2004] have shown for anonymous pairwise interactions that punishing activates reward-related brain areas, which suggests that people do derive satisfaction from sanctioning. Her such satisfaction is excluded. Individuals cannot impose direct sanctions on others. They can only contribute to the financing of an enforcement agency whose effectiveness depends, apart from technological conditions, from aggregate supply $E$.

${ }^{25}$ According to (17), $\frac{\partial g^{*}}{\partial e^{*}}>0$ if $(y-e) \frac{\alpha}{1-\alpha} \frac{1}{(1 / n+e)^{2}}>1+\frac{\alpha}{1-\alpha} \frac{1}{1 / n+e}$ which is equivalent to $(y-e) \frac{\alpha}{1-\alpha}>$ $\frac{1}{n^{2}}+\frac{2 e}{n}+e^{2}+\frac{\alpha}{1-\alpha}\left(\frac{1}{n}+e\right)$. Re-arranging terms we can rewrite this inequality as $\alpha y-\frac{\alpha}{n}-\frac{1-\alpha}{n^{2}}-$ $\left(2 \alpha+\frac{2(1-\alpha)}{n}\right) e>(1-\alpha) e^{2}$. Since $\alpha y-\frac{\alpha}{n}-\frac{1-\alpha}{n^{2}}>D(n)$ and $2 \alpha+\frac{2(1-\alpha)}{n}<k(n)$, this inequality holds at $e^{*}$ in view of condition (16).

${ }^{26}$ In the presented model, $e^{*}=0$ if no sanctioning is admitted i.e. if $\beta=0$.
} 
Proposition 2 . Voluntary contributions to public norm enforcement can support private provision of public goods even in large selfish societies in which no public good would be provided without enforcement. Under technology (14), $\lim _{n \rightarrow \infty} e^{*}(n)>0$ and $\lim _{n \rightarrow \infty} g^{*}(n)>0$ in a noncooperative equilibrium.

Table 1 shows numerical results for $y=100$ and $\alpha=0.75$, varying population sizes up to $n=10^{9}$. Without an enforcement problem the fully informed and benevolent planner would choose the public good share in aggregate income $G / Y$ equal to $1-\alpha=0.25$. For a level of per-capita income $y=100$, this implies that in a first best world per-capita contribution to the intrinsic public good would be equal to $g=25$. According to (14), without enforcement, i.e. if $E=0$, the degree of sanctioning or rewarding norm compliance is zero so that free-riding incentives are fully operating. The resulting noncooperative outcome is listed in the left half of Table 1. It shows that contributions to the public good vanish if $n$ gets large. In contrast, the right half shows the noncooperative outcome resulting when individuals have the possibility to contribute to a public enforcement funds.

\begin{tabular}{|c|c|c||c|c|c|}
\cline { 2 - 6 } \multicolumn{1}{c|}{} & \multicolumn{2}{c||}{ No enforcement $(E=0)$} & \multicolumn{2}{c|}{ Enforcement technology available } \\
\hline$n$ & $g^{0}$ & $V^{0}$ & $e^{*}$ & $g^{*}$ & $V^{*}$ \\
\hline \hline 10 & 3.23 & 73.55 & 0.85 & 23.84 & 100.45 \\
\hline $10^{3}$ & $0.33 \times 10^{-1}$ & 75.77 & 0.95 & 23.81 & 317.34 \\
\hline $10^{6}$ & $0.33 \times 10^{-4}$ & 75.79 & 0.95 & 23.81 & 1784.54 \\
\hline $10^{9}$ & $0.33 \times 10^{-7}$ & 75.79 & 0.95 & 23.81 & 10035.21 \\
\hline
\end{tabular}

Table 1: Noncooperative equilibrium when enforcement technology is not available (left half) / is available (right half). $y=100, g_{\text {FirstBest }}=25$. 
Adding $e^{*}$ to $g^{*}$ in Table 1, we come quite close to a public expenditure share of 25 percent in the noncooperative equilibrium. Part of this public expenditure is absorbed for the financing of public enforcement measures. Due to economies of scales in enforcement technology (14), this part shrinks as $n$ gets large. The results show very clearly that the noncooperative support of public good provision through public norm enforcement doesn't break down, and in fact may be quite efficient, even if economies are as large as the largest countries of the world. If no enforcement technology is available, free-riding is pervasive, in particular when population size is large. Comparison of utility level $V^{0}$ reached in the noncooperative equilibrium without enforcement to $V^{*}$ under enforcement shows the utility gains of public norm enforcement.

Given a society's gains from public norm enforcement it is worth to ask once more which kind of prerequisites are exactly needed? According to the above analysis, the only requirement is access to an enforcement technology and an entrepreneurial agent operating the technology. No central authority is needed to induce people to adopt the technology. Rational individuals voluntarily invest into the technology. Note also that no central authority has to know individual preferences for stipulating the norm that is enforced. According to (2), this norm emerges endogenously from individual contribution behavior. The reason for the noncooperative support of norm enforcement is its public character. Non-excludability of public good $E$ means that nobody can escape the enforcement measures financed by $E$. So my contribution $e_{i}$ exerts compliance pressure on me but on all others as well. Obviously, the assumption of non-rivalry of $E$ makes the enforcement particularly effective if $n$ is large. This is why the utility gains shown in Table 1 ( $V^{*}$ compared to utility levels $V^{0}$ achieved without enforcement possibility) are huge. In the next section the assumption of non-rivalry is dropped and $E$ will be a public good only insofar as nobody is excluded from its effects. 


\section{Noncooperative equilibrium when public enforce- ment resources are subject to full rivalry}

Suppose that instead of the absolute size of public enforcement funds the per-capita expenditure on public enforcement matters for the effectiveness of sanctioning free-riding. That means, the relevant enforcement technology is given by

$$
f(E, n)=1-\frac{1}{1+E / n}
$$

rather than by (14).

Then, the first-order condition characterizing individual contributions to the public enforcement funds is again a quadratic equation like (16), however with different parameters. We have: ${ }^{27}$

$$
\widetilde{D}(n)-\widetilde{k}(n) e=(1-\alpha) e^{2}
$$

where $\widetilde{D}(n) \equiv[(1-\alpha) y-1] \frac{\alpha}{1-\alpha} n-\alpha y-1$ and $\widetilde{k}(n)=(2-\alpha)\left(\frac{\alpha}{1-\alpha} n+1\right)+\alpha y$. Provided that $(1-\alpha) y>1$, we have $\partial \widetilde{D} / \partial n>0$ so that $\widetilde{D}(n)>0$ for $n$ above some minimal group size $\widetilde{n}_{0}$ at which $\widetilde{D}\left(\widetilde{n}_{0}\right)=0$. Moreover, $\widetilde{k}(n)>0$ and for $(1-\alpha) y>1$, the ratio $\widetilde{D} / \widetilde{k}$ is an increasing function of $n$ approaching $\widetilde{e} \equiv \frac{(1-\alpha) y-1}{2-\alpha} .{ }^{28}$ In sum, for $y>\frac{1}{1-\alpha}$ and $n>\widetilde{n}_{0}$, the solution of (19) is an increasing function $e^{*}(n)$ with $0<e^{*}(n)$ and $\lim _{n \rightarrow \infty} e^{*}(n)=\widetilde{e}<y$. (For $n \leq \widetilde{n}_{0}$, we have $e^{*}(n)=0$. $)^{29}$ Figure 2 illustrates this. Like in Figure 1 the negatively sloped line represents the left side of (19). As $n$ increases the line is shifted outward (dashed line), approaching - in contrast to Figure 1 - eventually the vertical line through $\widetilde{e}$.

${ }^{27}$ See Appendix $\mathrm{C}$ which considers enforcement technologies $f(E, n)=1-\frac{B}{1+E n^{-\gamma}}, 0<B \leq 1$, of any degree of rivalry $0 \leq \gamma \leq 1$. For $B=1$ and $\gamma=1$, (19) results. For the second-order condition see Appendix B.

${ }^{28} d(\widetilde{D} / \widetilde{k}) / d n>0$ if $[(1-\alpha) y-1]\left[(2-\alpha)\left(\frac{\alpha}{1-\alpha} n+1\right)+\alpha y\right]>\left\{[(1-\alpha) y-1] \frac{\alpha}{1-\alpha} n-\alpha y-1\right\}$ $(2-\alpha)$. This inequality is equivalent to $[(1-\alpha) y-1]\left(1+\frac{\alpha y}{2-\alpha}\right)+1+\alpha y>0$ which certainly holds for $(1-\alpha) y>1$.

${ }^{29}$ Again the threshold $\widetilde{n}$ is lowered if $y$ rises, since $\widetilde{D}(n)$ increases with $y$. 


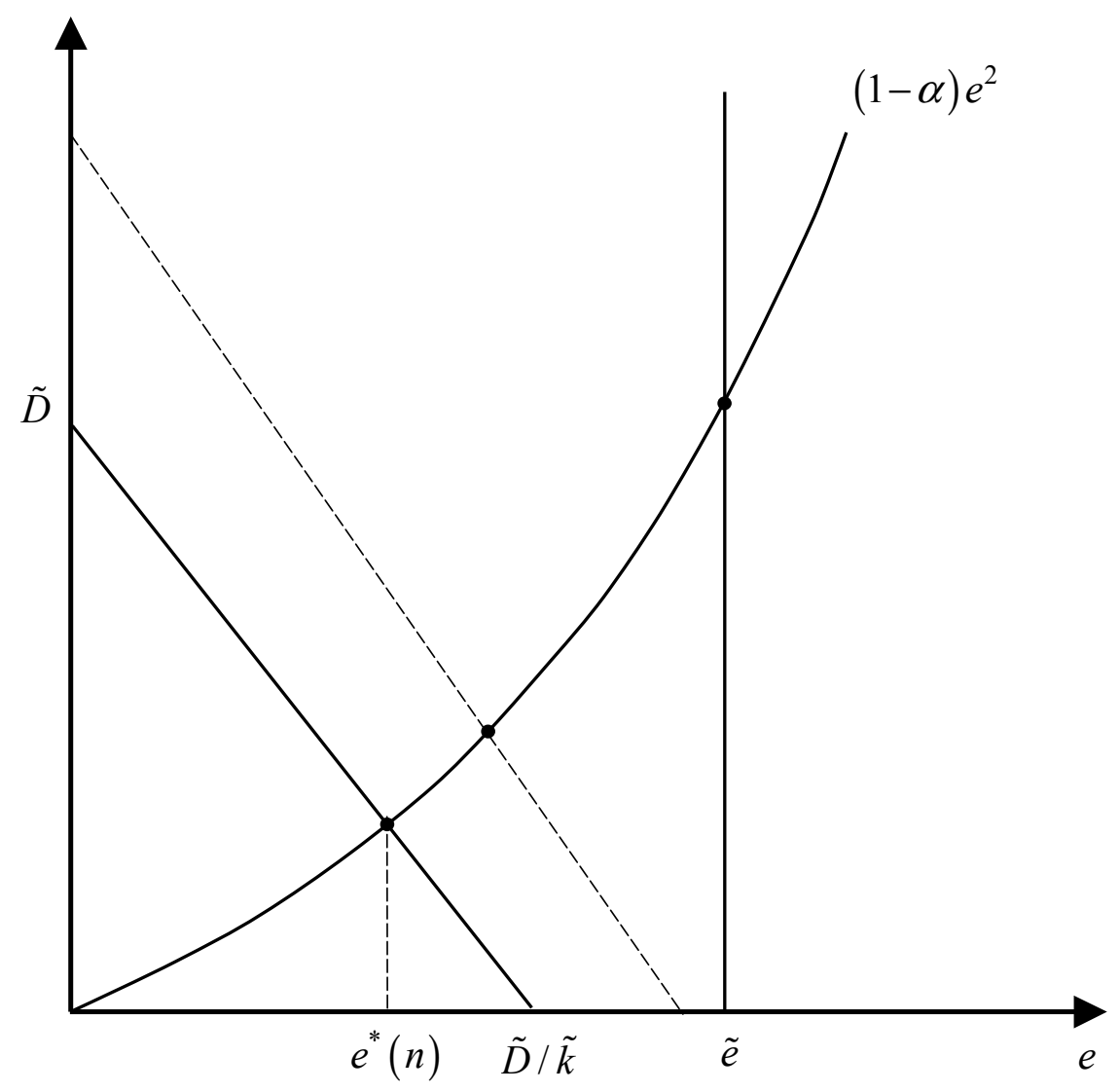

Figure 2: Equilibrium contribution to fully rival public enforcement.

Hence, economies of scale in the enforcement technology are not essential for the result that individuals make voluntary contributions to public enforcement also in large economies. Full rivalry doesn't destroy the incentives to invest into public enforcement. To the contrary, individuals may be inclined to give more for the enforcement funds. ${ }^{30}$ However, turning to Stage 2, we have now $\rho=\frac{\alpha}{1-\alpha}(1-\beta f)=\frac{\alpha}{1-\alpha}\left(1-\beta+\frac{\beta}{1+e}\right)$ and ${ }_{30} \widetilde{e}>\bar{e}$ if $\frac{(1-\alpha) y-1}{1-\alpha}>\frac{y(1-\alpha)}{2-\alpha+y(1-\alpha)}$ which is equivalent to $(1-\alpha)^{2} y^{2}-y(1-\alpha)>2-\alpha$. This inequality holds for $y$ sufficiently high. 
thus for $\beta=1$

$$
g^{*}(n)=\frac{y-e^{*}(n)}{1+\frac{\alpha}{1-\alpha} \frac{n}{1+e^{*}(n)}},
$$

according to (9).

Since $\lim _{n \rightarrow \infty} e^{*}(n)=\widetilde{e}<\infty, \lim _{n \rightarrow \infty} g^{*}(n)=0$. Thus, despite enforcement, contributions to the public good at Stage 2 eventually vanish. Table 2 shows that $g^{*}(n)$ can decline quite quickly. The reason is that with rivalry the enforcement technology is less efficient in the sense that the same volume of $E$ produces a lower degree of enforcement as $n$ rises. ${ }^{31}$ Therefore, the provided enforcement resources do not produce enough sanctioning strength at Stage 2 to overcome the strong free-riding incentives in the $G$-supply if $n$ is large. The following proposition summarizes this result. It should be noticed that parameter $\beta$ of nominal strength was held constant (by normalization to one). We will see later that this is a crucial restriction.

Proposition 3 . For a given nominal sanctioning strength $(\beta=1)$, if the enforcement technology is subject to rivalry: (i) Individuals keep contributing to public enforcement in large societies, provided that per-capita income is not too low $((1-\alpha) y>1)$. (ii) Individual contributions to the intrinsic public good eventually break down nonetheless.

The result does not say that the resources invested into public enforcement are useless. Otherwise rational people would not contribute in the first place. Table 2 shows $e^{*}, g^{*}$ and $V^{*}$ resulting under technology (18) in contrast to $g^{0}$ resulting when $E=0$. We see that $g^{*}$ is substantially higher than $g^{0}$ in Table 1 . Also $V^{*}$ is higher than $V^{0}$.

\footnotetext{
${ }^{31}$ As Isaac and Walker [1988] separated out very clearly in their experiments, under rivalry an increase of group size has also the effect that the marginal impact of an individual's contribution diminishes, in addition to the size effect observed in the case of a non-rival public enforcement resource $E$. Interestingly, this does not erode contributions to the second-order public good, in contrast to Isaac and Walker's findings for the case that a rival intrinsic public good is provided.
} 


\begin{tabular}{|c|c|c|c|}
\hline$n$ & $e^{*}$ & $g^{*}$ & $V$ \\
\hline \hline 10 & 5.59 & 17 & 94.23 \\
\hline $10^{3}$ & 18.77 & 0.53 & 129.19 \\
\hline $10^{6}$ & 19.20 & $0.54 \times 10^{-3}$ & 129.91 \\
\hline $10^{9}$ & 19.20 & $0.54 \times 10^{-6}$ & 129.91 \\
\hline
\end{tabular}

Table 2 Noncooperative equilibrium when enforcement technology is available but fully rival. $y=100, g_{\text {FirstBest }}=25$.

Proposition 3 shows that the problem of free-riding at Stage 2 is not due to secondorder free-riding at Stage 1. It occurs despite the fact that individuals provide public enforcement funds. The problem is that first-order (i.e. Stage 2) free-rider incentives in large societies are too strong to be overcome by the considered sanctioning device. A dictator who had the power to extract as much enforcement resource from the people as he wants would have the same problem. For any level of enforcement resource per-capita, for large $n, g^{*}(n)$ would vanish in the Stage 2-public good game, as can be seen by substituting any $e, 0<e<y$, for $e^{*}(n)$ in (20). This suggests that something is missing in the specification of the sanctioning system. To get an idea what, we have to call in mind what is a reasonable benchmark to which the noncooperative equilibrium should be compared. As discussed in the introduction, this benchmark is a central authority which is not constrained by the second-order free-rider problem but at Stage 2 also has to rely on norm enforcement by punishing and rewarding according to (2). Suppose that this central authority is a dictator as mighty as we can imagine. That means, he can set nominal strength $\beta$ of punishment and reward at his own discretion and can raise 
any level of enforcement resource $0<e<y$. Under technology (18), the degree of effective enforcement is bounded by $f<1-\frac{1}{1+y}$. Thus, how effectively nominal incentives for norm compliance can be implemented depends on per-capita income $y$. For making things better compatible, it seems reasonable to restrict the analysis to situations in which a dictator could achieve perfect enforcement, that means, reach a degree of enforcement $f$ equal to 1 at some feasible $\bar{e}<y$, regardless of size $n$ of the population. This is guarantied if function $f$ satisfies the following assumption.

Assumption 1. There exists $\bar{e}<y$ so that for any $n$, if $e \geq \bar{e}$ then $f(e n, n)=1$.

Since the dictator has the power to extract any $e<y$ he can always realize the maximal degree of enforcement. Moreover, he can choose nominal sanctioning strength $\beta$ at his discretion. The following lemma shows that, by using this power, a dictator is able to implement any level $g<y-\bar{e}$.

Lemma 1 Under Assumption 1, for any $n$ and $g<y-\bar{e}$, if $e=\bar{e}$, then $g^{*}(n)=g$ in the noncooperative equilibrium at Stage 2 for $\beta=1-\kappa / n$ with $\kappa=\frac{(1-\alpha)(y-\bar{e}-g)}{\alpha g}$.

Proof. By assumption, $f(\bar{e}, n)=1$. Thus, $1-\beta f=\kappa / n$ and $\rho=\frac{\alpha}{1-\alpha} \frac{\kappa}{n}$. Using this in (9), we get $g^{*}(n)=\frac{y-\bar{e}}{1+\frac{\alpha}{1-\alpha}} \kappa=\frac{y-\bar{e}}{g+y-\bar{e}-g} g=g$.

This shows: In groups of any size, it is possible to induce a desired level of contributions by a sanctioning system penalizing and rewarding deviations from the norm established by average contributions. However, to overcome the rising free-riding incentives in large societies, the allowed strength of sanctioning $\beta$ must be increasing with $n$. The difference between the above thought experiment about a dictator and the noncooperative support of public enforcement lies in Stage 1. A dictatorial central authority has the power to command enforcement means $\bar{e}$ by assumption. In a noncooperative explanation of public norm enforcement, the provision of $\bar{e}$ must be the equilibrium outcome at Stage 1. Whether or not this is possible is the subject of the further analysis. 
What we have learnt from the thought experiment is that effective norm enforcement in large societies requires two innovations if enforcement is subject to rivalry: First, there must be access to enforcement technologies which reach maximal enforcement at a feasible size of enforcement funds $\bar{e}<y$ (Assumption 1). Second, higher nominal sanctioning strength $\beta$ must be allowed as the economy gets larger. Again, in the noncooperative equilibrium, no central power is involved at Stage 1. Like before, we have the following situation: There is a device consisting of technology $f$ with $\max f=1$ together with a parameter $\beta$ defining the nominal sanctioning strength. An entrepreneurial agent offers to operate this technology at the level financed by voluntary contributions. An incentive expert has recommended to adjust parameter $\beta$ to population size according to the formula $\beta=1-\kappa / n$, where $\kappa$ is a constant. At Stage 1 , individuals decide noncooperatively how much they invest into this technology. At Stage 2, individuals contribute to the intrinsic public good under the public enforcement resulting from investments in the enforcement technology at Stage 1. I will show that Assumption 1 together with the adjustment of $\beta$ to group size is sufficient for explaining both public norm enforcement and the provision of the public good as outcome of a noncooperative equilibrium, also if the economy is very large.

Under technology (18), the upper bound is perfect enforcement. But it is never reached even if arbitrarily large enforcement resources are employed per individual. For making perfect enforcement technically feasible, we modify (18) as follows:

$$
f(E, n)=\left\{\begin{array}{lll}
A-\frac{B}{1+E / n} & \text { if } & E / n<\bar{e} \\
1 & \text { if } & E / n \geq \bar{e}
\end{array}\right.
$$

where $\bar{e}=\frac{B}{A-1}-1$ is the input required for perfect enforcement $(f(\bar{e} n, n)=1)$ and $A$, $B$ are parameters satisfying $0<B \leq A$ (so that $f \geq 0$ and $f_{E}>0$ for $E \geq 0$ ) and $1<A<B+1$ (guaranteeing $\bar{e}>0$ ). Parameter $A$ and $B$ allow for variations in the effectiveness of the available control technology. A rich variety of possible shapes of $f$ is covered by (21). Some reasons and interpretations for changes in $A$ or $B$ and their effects on the noncooperative equilibrium are discussed in Section 6. 
Under (21), Assumption 1 is guaranteed if $y>\frac{B}{A-1}-1(=\bar{e})$. Hence, according to Lemma 1 , any $g<y-\bar{e}$ can be implemented at Stage 2 , if $\bar{e}$ is provided at Stage 1 . The following lemma shows that this is indeed the case if $\beta$ is adjusted to group size.

Lemma 2 . Let $f$ be given by (21) with $\frac{B}{A-1}-1<y$. Let $\beta=\left(1-\frac{\kappa}{n}\right)$ with $1-\alpha<\kappa \leq 1$. There exists $\bar{n}$ so that for any $n \geq \bar{n}$ per-capita contributions to public enforcement in a noncooperative equilibrium are equal to $\bar{e}$.

Proof. Appendix D.

Since $e^{*}(n)=\bar{e}$, we have $\beta f=1-\frac{\kappa}{n}$ and $\rho=\frac{\alpha}{1-\alpha}(1-\beta f)=\frac{\alpha}{1-\alpha} \frac{\kappa}{n}$. Using this in (9), we get for per-capita contribution to the public good at Stage 2:

$$
g^{*}(n)=\frac{y-\bar{e}}{1+\frac{\alpha \kappa}{1-\alpha}}
$$

Since $1-\alpha<\kappa \leq 1$, we have $\frac{y-\bar{e}}{1+\alpha}>g^{*}(n) \geq(1-\alpha)(y-\bar{e})$.

Substituting $c=y-\bar{e}-g^{*}(n)$ and $G=n g^{*}(n)$ in (1), we obtain the utility level achieved by a member of the economy:

$$
V^{*}=\frac{(\alpha \kappa)^{\alpha}(1-\alpha)^{1-\alpha}}{1-\alpha+\alpha \kappa}(y-\bar{e}) .
$$

Thus, maximal welfare is achieved in a noncooperative equilibrium if parameter $\kappa=1$ in the design of the sanctioning system. In this case, we have $g^{*}(n)=(1-\alpha)(y-\bar{e})$. $\kappa<1$ means higher $\beta$. This would not change $e^{*}(n)$, the degree of enforcement is already maximal at $e^{*}(n)=\bar{e}$. But higher contributions to the intrinsic public good are induced at the cost of private consumption. This indicates that levying heavier penalties and rewards is not always a good idea. Since people provide the resources to effectively impose them, they may lead to overshooting contributions to the public cause. For $\kappa=1$, we have $e^{*}(n)+g^{*}(n)=(1-\alpha) y$. Thus, exactly the same share of public expenditure in income is provided in the noncooperative equilibrium as a benevolent planner would choose. However, in a first-best world all expenditures could be used for financing the 
intrinsic public good, whereas here part $\bar{e}$ is absorbed by enforcement activities. The following proposition summarizes these results.

Proposition 4. If enforcement technology (21) with $\bar{e}<y$ and nominal sanctioning strength $\beta=\left(1-\frac{\kappa}{n}\right), 1-\alpha<\kappa \leq 1$, is available, then for any size $n$ (except possibly small groups): (i) Individuals contribute $e^{*}(n)=\bar{e}$ to public enforcement so that sanctioning strength $\beta$ is enforced at maximal degree. (ii) Individual contributions to the intrinsic public good are positive and may even be too high from a welfare point of view. (iii) Welfare is maximal if $\kappa=1$, i.e. nominal sanctioning strength should not be unnecessarily high.

This establishes that size advantages of non-rival enforcement are not essential ${ }^{32}$ for "solving" the free-rider problem in large economies through noncooperative contributions to public norm enforcement. The important thing is the effectiveness of the feasible enforcement technology in relation to per-capita income. Either $y$ must be high enough to guarantee $\bar{e}<y$ for the given state of art of control technology $f$, or, for a given level of $y$, technical progress allows perfect enforcement at a sufficiently low level of resource input. This suggests that noncooperative support of public norm enforcement in large populations requires a certain state of development and that technical progress, for instance, inspection and information technologies that decrease the cost of observing deviating behavior, may lead to such support where it has not been present before.

\section{Discussion}

The goal of this analysis was to show that public norm enforcement and public good provision in large societies can result as equilibrium outcome of noncooperative interaction of individuals with standard economic preferences. This should not be seen as argument against altruistic or intrinsic motives for norm compliance. By intrinsic norm compliance

\footnotetext{
${ }^{32}$ In (21) the effectiveness of enforcement depends on per-capita resources $e$ and is invariant with respect to $n$.
} 
I mean that individuals have an internalized punishment and reward mechanism which induces them to contribute to a public good even though they don't have to fear any sanctioning by others or by a public enforcement institution. In the presented model, this means that the effective sanctioning factor in penalty-reward scheme (2) contains an intrinsic component $\beta_{0}$, in addition to component $\beta f$ resulting from the enforcement system, i.e. the effective sanctioning strength is $\widetilde{\beta}=\beta_{0}+\beta f$. For $\beta=1$ and $f=1-\frac{1}{1+E n^{-\gamma}}$, where $0 \leq \gamma \leq 1$ is used to cover both the case of non-rivalry specified by (14) and the case of rivalry specified by (18), we get the effective penalty-reward factor

$$
\widetilde{\beta}=\beta_{0}+1-\frac{1}{1+E n^{-\gamma}}
$$

and the effective "price" of contributing to the public good is $1-\widetilde{\beta}$ so that $\rho=\frac{\alpha}{1-\alpha}$ $\left(\frac{1}{1+E n^{-\gamma}}-\beta_{0}\right)$.

For $E=0$, we have $\widetilde{\beta}=\beta_{0}$ and

$$
\rho=\frac{\alpha}{1-\alpha}\left(1-\beta_{0}\right)
$$

instead of $\rho=\frac{\alpha}{1-\alpha}$ under specification (14) and (18) considered in Section 4 and 5. Using (25) in (9), we get for per-capita contribution without enforcement

$$
g^{0}=\frac{y}{1+\left(1-\beta_{0}\right) \frac{\alpha n}{1-\alpha}} .
$$

This shows very clearly how intrinsic norm compliance supports public good provision $\left(g^{0}\right.$ rises with $\left.\beta_{0}\right)$. In fact, in small groups it may be the only source of controlling freerider incentives since, according to our analysis, for low values of $n$ possibly no means of enforcement are provided in the noncooperative equilibrium at Stage 1. However, equation (26) also shows that public good provision based on intrinsic norm compliance alone breaks down when $n$ gets large. This leaves us with the question how other psychological factors may interact with public norm enforcement in large societies.

Section 5 has shown that, when enforcement resources are subject to rivalry, a necessary prerequisite for the emergence of public norm enforcement is the possibility to 
produce a maximal degree of enforcement at a feasible level of per-capita contribution to enforcement $\bar{e}<y$. A natural channel for the interaction of psychological factors and public norm enforcement is the following: Favorable psychological characteristics make effective enforcement easier. For instance, if individuals are more truthful, behavior can be more accurately verified with a given resource level $e$, i.e. ceteris paribus, the degree of enforcement rises. In our framework this corresponds to a rise of $A$ in (21). An immediate consequence is that the maximal degree of enforcement is already reached with a lower level of resources $\bar{e}$ spent on enforcement. Thus, the restriction $y>\bar{e}$ on the per-capita income required for the noncooperative support of effective public norm enforcement is more easily met. A further consequence of this kind of psychological augmentation of public enforcement is: The welfare level $V^{*}=\alpha^{\alpha}(1-\alpha)^{1-\alpha}(y-\bar{e})$ achieved in the noncooperative equilibrium increases.

Another psychological interaction could be that people react more or less sensitive to variations in enforcement activities. For instance, $f_{E}$ is high if they quickly reveal their behavior when watched by two rather than one investigator. This means that $B$ is affected in (21). Such an interaction between psychological characteristics and public norm enforcement has the following less obvious consequence. According to the proof of Lemma 2, the condition for $e^{*}(n)=\bar{e}$ in a noncooperative equilibrium under (21) and $\beta=\left(1-\frac{1}{n}\right)$ is equivalent to the inequality

$$
\frac{\alpha(n-1)^{2} n^{2}}{(1-\alpha)+\alpha / n} \geq \frac{(1-\bar{e})^{2}}{B(y-\bar{e})} .
$$

Thus, for any given values of $y, n, \alpha$ and $\bar{e}$, if sensitivity $B$ increases, the inequality guaranteeing an equilibrium with $e^{*}(n)=\bar{e}$ is more easily satisfied and noncooperative support of public norm enforcement becomes more likely. ${ }^{33}$

\footnotetext{
${ }^{33}$ Note that the inequality is also satisfied more likely if $y$ is high or if the public good $g$ has higher weight $\alpha$ in the individuals' preferences.
} 


\section{Conclusion}

In small groups mutual sanctioning and rewarding supports norm compliance of individual members in a decentralized way. If groups get large - in big associations or at the level of a whole society - specialized enforcement institutions take over the function of imposing norms by punishment and reward. This requires economic resources which the members of the society have to pay. The question that was addressed in this paper is: Why are they willing to pay? If norm enforcement was a private good, this would be a trivial question. However, enforcing a norm involves a twofold public good problem. First, complying with a norm means that individuals contribute a certain amount to a public good. This is why norm compliance is desirable in the first place. Second, enforcing norm compliance is also a public good since nobody can be excluded from the benefits of effective enforcement. Thus, in addition to the incentive to free-ride on others by contributing less than the norm to some public good there is a second-level free-rider motive to let other pay for the funds required for financing an enforcement institution.

The contribution of this paper is to show how public norm enforcement can emerge as decentralized equilibrium in large societies of individuals with standard economic preferences. This is achieved by a new approach to the private provision of the second-order public good norm enforcement. Rather than starting from a model in which an economy is a tabula rasa on which individuals with given preferences and endowments interact, this paper takes the standard view of general equilibrium analysis that in any given situation a real economy consists of three fundamentals, including technology in addition to endowments and preferences. The basic assumption of the paper is that private agents can operate monitoring technologies (information acquisition about individual behavior,

instruments of punishment and reward), provided they can raise a sufficient amount of resources, just as managers or entrepreneurial agents run production technologies of firms in a private market equilibrium. The essential difference is that the produced good "norm enforcement" is a public good so that the noncooperative provision of the funds that can be invested in the enforcement technology is subject to the free-riding problem. It was 
shown that nonetheless noncooperative provision of public enforcement funds is sustained even if group size increases to infinity. Whether or not the provided enforcement funds suffice to induce substantial contributions to the intrinsic public good at the second stage depends on the effectiveness of the available technology. However, it was shown that even in economies as large as the largest countries in the world an almost efficient level of public good provision may result in the considered noncooperative two stage equilibrium.

Intuitively, the results may be best understood by focussing on the external effects involved in the double public good problem. At each stage - the provision of public enforcement resources and the provision of the intrinsicly valued public good, respectively individual contributions have positive externalities on other individuals. If the two stages are considered in isolation, these externalities lead to underprovision of the respective public good. However, contributions to the public enforcement resource exert a negative externality on others in the following first-order contribution game. The free-riding possibilities in this game are reduced if more is contributed to the public enforcement funds. In sum, the externalities working in opposite directions do not accentuate the market failure in public good provision but help to cure it.

The fact that an institution, enforcing public good provision, is economically supported in a decentralized equilibrium of arbitrarily large populations provides an individualistic explanation for why large associations with effective norms and collective goods emerge or are sustained. No exogenous power was assumed nor any bargaining or social contract. The two prerequisites are: Availability of an enforcement technology and feasibility of economic penalties and rewards as instruments for sanctioning. An enforcement institution emerges or is sustained in a population of autonomous agents if their individual decisions to invest in that opportunity generates enough resources to realize it effectively. The focus of this paper was to prove that even individuals with standard economic preferences may voluntarily provide the economic means for an effective public sanctioning system with the purpose to guarantee the provision of a public good. Psychological factors like intrinsic norm compliance, sincerity, or sensitivity to punishment and reward can augment the 
purely economic interests. In the presented framework, such psychological factors work like a productivity progress in the feasible enforcement technology.

The presented model is silent on the endogenous evolution of enforcement technologies over time. However, it is consistent with the following view on the development of norms and institutions - be it past or future history. In a given historical situation, there is a feasible set of production possibilities to which private agents have access. The scale at which a technology can be run by an individual or private agency without exogenous coercive power depends on how much funds can be raised by voluntary contributions. This in turn depends - apart from people's preferences and endowments - on the effectiveness of the technologies. Obviously, the effectiveness of production possibilities is a function of many dimensions of the state of development - the available technical tools, the organizational and psychological Know-how, but also already existing institutions can be exploited. Thus, if we ask, for instance, if in the future a private agency will be able to enforce certain behavioral norms at a world wide scale - inducing compliance with environmental, ethic or security standards at a non-negligible degree - we have to account for the fact that such an agency, like firms in conventional production, have access to the state of arts, including the Know-how how to use existing private or public institutions. In the same way, we have to be aware that in any moment of past history private agents could use the state of art at their time. This paper has shown that in this way public norm enforcement can emerge as a decentralized equilibrium even in a very large population. I do not claim that this is the only channel. For instance, when such a private agency has got substantial norm enforcing power by noncooperative support, cooperative forces may step in and require to control this power by contracts, voting procedures or integration into politically controlled public institutions. In any case, they become part of the set of Know-how and instruments defining the production possibilities that can be used for the production of norm enforcement from then on. In this sense, I think the shown possibility of noncooperative emergence of norm enforcement is a key element in the development of institutions, in particular of institutions covering large populations. 


\section{REFERENCES}

Andreoni, James [1988], "Privately Provided Public Goods in a Large Economy: The Limits of Altruism", Journal of Public Economics 35, pp. 57-73.

Andreoni, James, and Theodore C. Bergstrom [1996], "Do Government Subsidies Increase the Private Supply of Public Goods?" Public Choice, 88(3-4), pp. 295308.

Bergstrom, Theodore C., Lawrence Blume, and Hal R.Varian [1986], "On the Private Provision of Public Goods", Journal of Public Economics 29(1), pp. 25-49.

Bernheim, B. Douglas [1994], "A Theory of Conformity", Journal of Political Economy 102(5), pp. 841-877.

Boadway, Robin, Pierre Pestieau, and David Wildasin [1989], "Tax-Transfer Policies and the Voluntary Provision of Public Goods", Journal of Public Economics 39(2), pp. 157-176.

Brunner, Johann K., and Josef Falkinger [1999], "Taxation in an Economy with Private Provision of Public Goods", Review of Economic Design 4, pp. 357-379.

Carpenter, Jeffrey P. [2004], "Punishing Free-Riders: How Group Size Affects Mutual Monitoring and the Provision of Public Goods", mimeo.

Chen, Yan [forthcoming], "Dynamic Stability of Nash-Efficient Public Goods Mechanisms: Reconciling Theory and Experiments", in: Rami Zwick and Amnon Rapoport, eds., Experimental Business Research, Volume II, Norwell, MA and Dordrecht: Kluwer.

Coleman, James S. [1990], Foundations of Social Theory, Cambridge/M.: Harvard University Press. 
Cornes, Richard C., and Todd Sandler [1986], The theory of externalities, public goods, and club goods, Cambridge/M., Cambridge University Press.

de Quervain, Dominique J.F., Urs Fischbacher, Valery Treyer, Melanie Schellhammer, Ulrich Schnyder, Alfred Buck, and Ernst Fehr [2004], "The Neural Basis of Altruistic Punishment", Science 305, pp. 1254-1258.

Falkinger, Josef [1996], "Efficient Private Provision of Public Goods by Rewarding Deviations from Average", Journal of Public Economics 62, pp. 413-422.

Falkinger, Josef, Ernst Fehr, Simon Gächter, and Rudolf Winter-Ebmer [2000], "A Simple Mechanism for the Efficient Private Provision of Public Goods: Experimental Evidence", American Economic Review 90, pp. 247-264.

Fehr, Ernst, and Urs Fischbacher [2003], "The Nature of Human Altruism - Proximate Patterns and Evolutionary Origins", Nature 425, pp. 785-791.

Fehr, Ernst, and Simon Gächter [2000], "Cooperation and Punishment in Public Goods Experiments", American Economic Review 90, pp. 980-994.

Fehr, Ernst, and Simon Gächter [2002], "Altruistic Punishment in Humans", Nature 415, pp. 137-140.

Huck, Steffen, and Michael Kosfeld [2004], "The Dynamics of Neighbourhood Watsch and Norm Enforcement", Working Paper No. 199 of the Institute for Empirical Research in Economics, University of Zurich.

Isaac, R. Mark, and James M. Walker [1988], "Group Size Effects in Public Goods Provision: The Voluntary Contribution Mechanism", The Quarterly Journal of Economics 103, pp. 179-199.

Isaac, R. Mark, James M. Walker, and Arlington W. Williams, [1994], "Group size and the voluntary provision of public goods", Journal of Public Economics 54, pp. 1-36. 
Kosfeld, Michael, and Arno Riedl [2004], "The Design of (De)centralized Punishment Institutions for Sustaining Cooperation", Tinbergen Institute, Discussion Paper TI 2004-025/1.

Ledyard, John O. [1995], "Public Goods: A Survey of Experimental Research", in: Alvin E. Roth and John Kagel, eds., Handbook of Experimental Economics, NJ: Princeton University Press, pp. 111-194.

Okada, Akira [1993], "The Possibility of Cooperation in an $n$-Person Prisoners' Dilemma with Institutional Arrangements", Public Choice 77, pp. 629-656.

Okada, Akira [1997], "The Organization of Social Cooperation: A Noncooperative Approach", in: W. Albers et al. (eds.), Understanding Strategic Interaction. Essays in Honor of Reinhard Selten, Springer: Berlin et al., pp. 228-242.

Olson, Mancur [1965], The Logic of Collective Action: Public Goods and the Theory of Groups, Cambridge/M.: Harvard University Press.

Roberts, Russel D. [1987], "Financing Public Goods", Journal of Political Economy 95(2), pp. $420-437$.

Roberts, Russel D. [1992], "Government Subsidies to Private Spending on Public Goods", Public Choice 74(2), pp. 133-152.

Sethi, Rajiv, and E. Somanathan [1996], "The Evolution of Social Norms in Common Property Resource Use", American Economic Review 86(4), pp. 766-788.

Skyrms, Brian [1996], Evolution of the Social Contract, Cambridge et al., Cambridge University Press.

Yamagishi, Tashio [1986], "The Provision of a Sanctioning System as a Public Good", Journal of Personality and Social Psychology 51, pp. 110-116.

Varian, Hal R. [1994a], "Sequential Contributions to Public Goods", Journal of Public Economics 53(2), pp. 165-186. 
Varian, Hal R. [1994b], "A Solution to the Problem of Externalities When Agents Are Well-Informed", American Economic Review 84(5), pp. 1278-1293. 


\section{Appendix A}

Let preferences of individuals $i=1, \ldots, n$ be given by utility functions $U^{i}(c, G)$, where both $c$ and $G$ are assumed to be normal goods. For a given $n$, let $\widetilde{\beta}(E) \equiv \beta f(E, n)$.

At Stage 2, individual $i$ chooses $g_{i}$ so that

$$
M R S^{i}\left(c_{i}, G\right) \leq 1-\beta(E), \quad M R S^{i} \equiv \frac{U_{G}^{i}}{U_{c}^{i}}
$$

with equality holding if $g_{i}>0$.

Substituting(6) for $G$ in condition (4), we get for all $i$ with positive contributions the equation

$$
M R S^{i}\left(c_{i}, Y-E-C\right)=1-\widetilde{\beta}(E)
$$

which defines an implicit function $c_{i}(Y, C, E)$ with $^{34} \frac{\partial c_{i}}{\partial Y}=-\frac{M R S_{G}^{i}}{M R S_{c}^{i}}>0, \frac{\partial c_{i}}{\partial C}=-\frac{\partial c_{i}}{\partial Y}<0$ and $\frac{\partial c_{i}}{\partial E}=\frac{\partial c_{i}}{\partial C}-\frac{\widetilde{\beta}^{\prime}}{M R S_{c}^{i}}<0$.

Under the assumption that all individuals contribute a positive amount $g_{i}$ so that (A.2) holds for $1, \ldots, n$, aggregation gives us $\sum_{i=1}^{n} c_{i}(Y, C, E)=C$. This equation implicitly defines

$$
C=Z(Y, E)
$$

with $\frac{\partial Z}{\partial Y}=\frac{\sum_{i=1}^{n} \frac{\partial c^{i}}{\partial Y}}{1-\sum_{i=1}^{n} \frac{\partial c^{i}}{\partial C}}>0$ and $\frac{\partial Z}{\partial E}=\frac{\sum_{i=1}^{n} \frac{\partial c^{i}}{\partial E}}{1-\sum_{i=1}^{n} \frac{\partial c^{i}}{\partial C}}<0$.

Substituting $Z(Y, E)$ for $C$ in $c^{i}(Y, C, E)$, we get

$$
c_{i}=z^{i}(Y, E)
$$

with $z^{i}(Y, E) \equiv c^{i}(Y, Z(Y, E), E)$.

\footnotetext{
${ }^{34}$ If both $c$ and $G$ are normal goods, then $M R S_{G}^{i}\left(\equiv \frac{\partial M R S^{i}}{\partial G}\right)<0$ and $M R S_{c}^{i}>0$.
} 
Combining (3), (4), (6) with (A.3), (A.4) and solving for $g_{i}$ we get

$$
g_{i}=\frac{(n-1)\left[y_{i}-e_{i}-z^{i}(Y, E)\right]-\widetilde{\beta}(E)[Y-E-Z(Y, E)]}{n(1-\widetilde{\beta}(E))-1} .
$$

(Use $\bar{g}_{-i}=\frac{G}{n-1}-\frac{g_{i}}{n-1}$.) This characterizes the Stage 2 equilibrium strategies as functions of the Stage 1 outcome $e_{i}, E$.

At Stage 1, individual $i$ 's decision problem is

$$
\max _{e_{i}} U^{i}\left(c_{i}, G\right)
$$

where $c_{i}=z^{i}\left(Y, e_{i}+E_{-i}\right)$ and $G=Y-\left(e_{i}+E_{-i}\right)-Z\left(Y, e_{i}+E_{-i}\right)$ is anticipated from the Stage 2 equilibrium.

Differentiating (A.6) with respect to $e_{i}$, we get the first-order condition

$$
M R S^{i}\left(c_{i}, G\right)=\frac{\frac{\partial z^{i}}{\partial E}}{1+\frac{\partial Z}{\partial E}}
$$

for an individual contributing a positive amount $e_{i}$ to the public enforcement funds.

Combining (A.7) with (A.1), we obtain as a necessary condition for an equilibrium in which all individuals contribute:

$$
[1-\widetilde{\beta}(E)]\left(1+\frac{\partial Z(Y, E)}{\partial E}\right)=\frac{\partial z^{i}(Y, E)}{\partial E} .
$$

The condition defines the size of enforcement funds $E$ as a function of $Y$. 


\section{Appendix B}

Differentiating first-order condition (13), we get

$$
\frac{\partial F}{\partial E}=-\alpha\left(\frac{\rho_{E}}{\rho}\right)^{2}+\left[\frac{n \rho_{E}}{1+\rho n}\right]^{2}+\left[\frac{\alpha}{\rho}-\frac{n}{1+\rho n}\right] \rho_{E E}-\frac{1}{(Y-E)^{2}} .
$$

At $F=0$, the first square-bracketed term equals $\frac{\alpha \rho_{E}}{\rho}-\frac{1}{Y-E}$ and the second squarebracketed term equals $\frac{1}{Y-E} \frac{1}{\rho_{E}}$. Thus, at $F=0, \quad \frac{\partial F}{\partial E}=-\alpha\left(\frac{\rho_{E}}{\rho}\right)^{2}+\left[\frac{\alpha \rho_{E}}{\rho}-\frac{1}{Y-E}\right]^{2}$ $+\frac{1}{Y-E} \frac{\rho_{E E}}{\rho_{E}}-\frac{1}{(Y-E)^{2}}=\left(\frac{\rho_{E}}{\rho}\right)^{2}\left(a^{2}-\alpha\right)-2 \frac{\alpha \rho_{E}}{\rho} \frac{1}{Y-E}+\frac{1}{Y-E} \frac{\rho_{E E}}{\rho_{E}}=-\alpha(1-\alpha)\left(\frac{\rho_{E}}{\rho}\right)^{2}-$ $\frac{1}{Y-E}\left(\frac{2 \alpha \rho_{E}}{\rho}-\frac{\rho_{E E}}{\rho_{E}}\right)$ so that the second-order condition is equivalent to the inequality

$$
-\alpha(1-\alpha)(Y-E)\left(\frac{\rho_{E}}{\rho}\right)^{2}<2 \alpha \frac{\rho_{E}}{\rho}-\frac{\rho_{E E}}{\rho_{E}} .
$$

Using $\rho=\frac{\alpha}{1-\alpha}(1-\beta f), \rho_{E}=-\frac{\alpha}{1-\alpha} \beta f_{E}$ and $\rho_{E E}=-\frac{\alpha}{1-\alpha} \beta f_{E E}$, we get $-\alpha(1-\alpha)(Y-E)\left(\frac{\beta f_{E}}{1-\beta f}\right)^{2}<-2 \alpha \beta \frac{f_{E}}{1-\beta f}-\frac{f_{E E}}{f_{E}}$ which is equivalent to

$$
-\alpha(1-\alpha)(Y-E) \frac{\left(\beta f_{E}\right)^{2}}{1-\beta f}<-\left[2 \alpha \beta f_{E}+\frac{f_{E E}}{f_{E}}(1-\beta f)\right] .
$$

Thus, a sufficient condition is

$$
2 \alpha \beta f_{E}+\frac{f_{E E}}{f_{E}}(1-\beta f)<0
$$

Case: $f=A-\frac{B}{1+E n^{-\gamma}}$.

In this case, $f_{E}=\frac{B n^{-\gamma}}{\left(1+E n^{-\gamma}\right)^{2}}$ and $f_{E E}=-\frac{B n^{-\gamma} 2\left(1+E n^{-\gamma}\right) n^{-\gamma}}{\left(1+E n^{-\gamma}\right)^{4}}$ so that inequality (B.4) reduces to $2 \alpha \beta \frac{B n^{-\gamma}}{\left(1+E n^{-\gamma}\right)^{2}}<\frac{2 n^{-\gamma}}{1+E n^{-\gamma}}(1-\beta f)$ which is equivalent to $\alpha \beta B<\left(1+E n^{-\gamma}\right)$ $(1-\beta f)=\left(1+E n^{-\gamma}\right)(1-\beta A)+\beta B$. Rearranging terms, we have

$$
\beta B(\alpha-1)<1+E n^{-\gamma}
$$

which holds since $\alpha<1$. 


\section{Appendix C}

Let $f=1-\frac{B}{1+E n^{-\gamma}}, 0<B \leq 1,0 \leq \gamma \leq 1$, and $\beta=1$. Then, $\rho=\frac{\alpha}{1-\alpha}(1-\beta f)=$ $\frac{\alpha}{1-\alpha} \frac{B}{1+E n^{-\gamma}}$ and $\rho_{E}=-\frac{\alpha}{1-\alpha} \frac{B n^{-\gamma}}{\left(1+E n^{-\gamma}\right)^{2}}$. Using this in (13), we get $F=\left[\frac{1}{B}-\frac{n}{(1-\alpha)\left(1+E n^{-\gamma}\right)+n \alpha B}\right]$ $\frac{-\alpha B n^{-\gamma}}{\left(1+E n^{-\gamma}\right)}-\frac{1}{Y-E}=0$. This is equivalent to $\left[\frac{\alpha \beta}{(1-\alpha)\left(1 / n+e n^{-\gamma}\right)+\alpha B}-\alpha\right]=\frac{n^{\gamma}\left(1 / n+e n^{-\gamma}\right)}{y-e}$ which can be rewritten as $\alpha B(y-e)-\alpha(1-\alpha)\left(\frac{1}{n}+e n^{-\gamma}\right)(y-e)-\alpha^{2} B(y-e)=n^{\gamma}\left(\frac{1}{n}+e n^{-\gamma}\right)^{2}$ $(1-\alpha)+n^{\gamma}\left(\frac{1}{n}+e n^{-\gamma}\right) \alpha B$ and further transformed to $(1-\alpha) \alpha B(y-e)-\alpha(1-\alpha)$ $\left(n^{\gamma-1}+e\right) n^{-\gamma}(y-e)=n^{\gamma}\left(\frac{1}{n^{2}}+2 \frac{e}{n} e^{-\gamma}+e^{2} n^{-2 \gamma}\right)(1-\alpha)+\left(n^{\gamma-1}+e\right) \alpha B$.

Multiplying both sides of the equation by $n^{\gamma}$, we get $(1-\alpha) \alpha B y n^{\gamma}-\alpha(1-\alpha) n^{\gamma-1} y-$ $(1-\alpha) \alpha B n^{\gamma} e+\alpha(1-\alpha) n^{\gamma-1} e-\alpha(1-\alpha) y e+\alpha(1-\alpha) e^{2}=n^{2 \gamma-2}(1-\alpha)$ $+2 n^{\gamma-1}(1-\alpha) e+e^{2}(1-\alpha)+n^{2 \gamma-1} \alpha B+\alpha B n^{\gamma} e$.

After division by $1-\alpha$ and collection of terms this equation reduces to $D(\gamma)-k(e) e=$ $(1-\alpha) e^{2}$ with

$$
D(\gamma)=\alpha B n^{\gamma} y-\alpha n^{\gamma-1} y-\frac{\alpha B}{1-\alpha} n^{2 \gamma-1}-n^{2 \gamma-2}
$$

and

$$
k(\gamma)=\frac{(2-\alpha) \alpha B n^{\gamma}}{1-\alpha}+\alpha y+(2-\alpha) n^{\gamma-1}
$$

With $B=1$ these terms reduce for $\gamma=0$ to $D, k$ and for $\gamma=1$ to $\widetilde{D}, \widetilde{k}$ in the main text. QED.

\section{Appendix D}

Suppose that $e^{*}(n)<\bar{e}$. Then, according to (13), $F=0$ at $e^{*}(n)$ or $e^{*}(n)=0$. In any case, $F<0$ at $\bar{e}$, since according to Appendix B, $F^{\prime}<0$ whenever $F=0$. Hence, if $F \geq 0$ at $\bar{e}$, then $e^{*}(n)=\bar{e}$. Now, at $\bar{e}$ we have $\rho=\frac{\alpha}{1-\alpha}(1-\beta)=\frac{\alpha}{1-\alpha} \frac{\kappa}{n}$ and $\rho_{E}=-\frac{\alpha}{1-\alpha} \beta \frac{B / n}{(1+\bar{e})^{2}}=-\frac{\alpha}{1-\alpha}(n-\kappa) \frac{B}{(1+\bar{e})^{2}}$.

Thus, $F=\left[(1-\alpha) \frac{n}{\kappa}-\frac{n}{1+\frac{\alpha}{1-\alpha} \frac{\kappa}{n}}\right] \frac{-\alpha}{1-\alpha}(n-\kappa) \frac{B}{(1+\bar{e})^{2}}-\frac{1}{n(y-\bar{e})} \geq 0$ iff $\frac{\alpha(n-\kappa)}{\kappa} \frac{\kappa n-(1-\alpha) n-\alpha \kappa}{1-\alpha+\alpha \frac{\kappa}{n}}$ $\geq \frac{(1+\bar{e})^{2}}{B n^{2}(y-\bar{e})}$. This inequality is equivalent to $\frac{\alpha(n-\kappa)}{\kappa} \frac{(\kappa+\alpha-1) n-\alpha \kappa}{1-\alpha+\alpha \frac{\kappa}{n}} \geq \frac{(1+\bar{e})^{2}}{B n^{2}(y-\bar{e})}$. For $\kappa>1-\alpha$ the left side increases with $n$, whereas the right side decreases. Thus there exists a threshold $\bar{n}$ above which the inequality holds. QED. 


\section{CESifo Working Paper Series}

(for full list see www.cesifo.de)

1305 Julia Darby, Anton Muscatelli and Graeme Roy, Fiscal Federalism, Fiscal Consolidations and Cuts in Central Government Grants: Evidence from an Event Study, October 2004

1306 Michael Waldman, Antitrust Perspectives for Durable-Goods Markets, October 2004

1307 Josef Honerkamp, Stefan Moog and Bernd Raffelhüschen, Earlier or Later: A General Equilibrium Analysis of Bringing Forward an Already Announced Tax Reform, October 2004

1308 M. Hashem Pesaran, A Pair-Wise Approach to Testing for Output and Growth Convergence, October 2004

1309 John Bishop and Ferran Mane, Educational Reform and Disadvantaged Students: Are They Better Off or Worse Off?, October 2004

1310 Alfredo Schclarek, Consumption and Keynesian Fiscal Policy, October 2004

1311 Wolfram F. Richter, Efficiency Effects of Tax Deductions for Work-Related Expenses, October 2004

1312 Franco Mariuzzo, Patrick Paul Walsh and Ciara Whelan, EU Merger Control in Differentiated Product Industries, October 2004

1313 Kurt Schmidheiny, Income Segregation and Local Progressive Taxation: Empirical Evidence from Switzerland, October 2004

1314 David S. Evans, Andrei Hagiu and Richard Schmalensee, A Survey of the Economic Role of Software Platforms in Computer-Based Industries, October 2004

1315 Frank Riedel and Elmar Wolfstetter, Immediate Demand Reduction in Simultaneous Ascending Bid Auctions, October 2004

1316 Patricia Crifo and Jean-Louis Rullière, Incentives and Anonymity Principle: Crowding Out Toward Users, October 2004

1317 Attila Ambrus and Rossella Argenziano, Network Markets and Consumers Coordination, October 2004

1318 Margarita Katsimi and Thomas Moutos, Monopoly, Inequality and Redistribution Via the Public Provision of Private Goods, October 2004

1319 Jens Josephson and Karl Wärneryd, Long-Run Selection and the Work Ethic, October 2004 
1320 Jan K. Brueckner and Oleg Smirnov, Workings of the Melting Pot: Social Networks and the Evolution of Population Attributes, October 2004

1321 Thomas Fuchs and Ludger Wößmann, Computers and Student Learning: Bivariate and Multivariate Evidence on the Availability and Use of Computers at Home and at School, November 2004

1322 Alberto Bisin, Piero Gottardi and Adriano A. Rampini, Managerial Hedging and Portfolio Monitoring, November 2004

1323 Cecilia García-Peñalosa and Jean-François Wen, Redistribution and Occupational Choice in a Schumpeterian Growth Model, November 2004

1324 William Martin and Robert Rowthorn, Will Stability Last?, November 2004

1325 Jianpei Li and Elmar Wolfstetter, Partnership Dissolution, Complementarity, and Investment Incentives, November 2004

1326 Hans Fehr, Sabine Jokisch and Laurence J. Kotlikoff, Fertility, Mortality, and the Developed World's Demographic Transition, November 2004

1327 Adam Elbourne and Jakob de Haan, Asymmetric Monetary Transmission in EMU: The Robustness of VAR Conclusions and Cecchetti's Legal Family Theory, November 2004

1328 Karel-Jan Alsem, Steven Brakman, Lex Hoogduin and Gerard Kuper, The Impact of Newspapers on Consumer Confidence: Does Spin Bias Exist?, November 2004

1329 Chiona Balfoussia and Mike Wickens, Macroeconomic Sources of Risk in the Term Structure, November 2004

1330 Ludger Wößmann, The Effect Heterogeneity of Central Exams: Evidence from TIMSS, TIMSS-Repeat and PISA, November 2004

1331 M. Hashem Pesaran, Estimation and Inference in Large Heterogeneous Panels with a Multifactor Error Structure, November 2004

1332 Maarten C. W. Janssen, José Luis Moraga-González and Matthijs R. Wildenbeest, A Note on Costly Sequential Search and Oligopoly Pricing, November 2004

1333 Martin Peitz and Patrick Waelbroeck, An Economist's Guide to Digital Music, November 2004

1334 Biswa N. Bhattacharyay and Prabir De, Promotion of Trade, Investment and Infrastructure Development between China and India: The Case of Southwest China and East and Northeast India, November 2004

1335 Lutz Hendricks, Why Does Educational Attainment Differ Across U.S. States?, November 2004

1336 Jay Pil Choi, Antitrust Analysis of Tying Arrangements, November 2004 
1337 Rafael Lalive, Jan C. van Ours and Josef Zweimueller, How Changes in Financial Incentives Affect the Duration of Unemployment, November 2004

1338 Robert Woods, Fiscal Stabilisation and EMU, November 2004

1339 Rainald Borck and Matthias Wrede, Political Economy of Commuting Subsidies, November 2004

1340 Marcel Gérard, Combining Dutch Presumptive Capital Income Tax and US Qualified Intermediaries to Set Forth a New System of International Savings Taxation, November 2004

1341 Bruno S. Frey, Simon Luechinger and Alois Stutzer, Calculating Tragedy: Assessing the Costs of Terrorism, November 2004

1342 Johannes Becker and Clemens Fuest, A Backward Looking Measure of the Effective Marginal Tax Burden on Investment, November 2004

1343 Heikki Kauppi, Erkki Koskela and Rune Stenbacka, Equilibrium Unemployment and Capital Intensity Under Product and Labor Market Imperfections, November 2004

1344 Helge Berger and Till Müller, How Should Large and Small Countries Be Represented in a Currency Union?, November 2004

1345 Bruno Jullien, Two-Sided Markets and Electronic Intermediaries, November 2004

1346 Wolfgang Eggert and Martin Kolmar, Contests with Size Effects, December 2004

1347 Stefan Napel and Mika Widgrén, The Inter-Institutional Distribution of Power in EU Codecision, December 2004

1348 Yin-Wong Cheung and Ulf G. Erlandsson, Exchange Rates and Markov Switching Dynamics, December 2004

1349 Hartmut Egger and Peter Egger, Outsourcing and Trade in a Spatial World, December 2004

1350 Paul Belleflamme and Pierre M. Picard, Piracy and Competition, December 2004

1351 Jon Strand, Public-Good Valuation and Intrafamily Allocation, December 2004

1352 Michael Berlemann, Marcus Dittrich and Gunther Markwardt, The Value of NonBinding Announcements in Public Goods Experiments: Some Theory and Experimental Evidence, December 2004

1353 Camille Cornand and Frank Heinemann, Optimal Degree of Public Information Dissemination, December 2004

1354 Matteo Governatori and Sylvester Eijffinger, Fiscal and Monetary Interaction: The Role of Asymmetries of the Stability and Growth Pact in EMU, December 2004 
1355 Fred Ramb and Alfons J. Weichenrieder, Taxes and the Financial Structure of German Inward FDI, December 2004

1356 José Luis Moraga-González and Jean-Marie Viaene, Dumping in Developing and Transition Economies, December 2004

1357 Peter Friedrich, Anita Kaltschütz and Chang Woon Nam, Significance and Determination of Fees for Municipal Finance, December 2004

1358 M. Hashem Pesaran and Paolo Zaffaroni, Model Averaging and Value-at-Risk Based Evaluation of Large Multi Asset Volatility Models for Risk Management, December 2004

1359 Fwu-Ranq Chang, Optimal Growth and Impatience: A Phase Diagram Analysis, December 2004

1360 Elise S. Brezis and François Crouzet, The Role of Higher Education Institutions: Recruitment of Elites and Economic Growth, December 2004

1361 B. Gabriela Mundaca and Jon Strand, A Risk Allocation Approach to Optimal Exchange Rate Policy, December 2004

1362 Christa Hainz, Quality of Institutions, Credit Markets and Bankruptcy, December 2004

1363 Jerome L. Stein, Optimal Debt and Equilibrium Exchange Rates in a Stochastic Environment: an Overview, December 2004

1364 Frank Heinemann, Rosemarie Nagel and Peter Ockenfels, Measuring Strategic Uncertainty in Coordination Games, December 2004

1365 José Luis Moraga-González and Jean-Marie Viaene, Anti-Dumping, Intra-Industry Trade and Quality Reversals, December 2004

1366 Harry Grubert, Tax Credits, Source Rules, Trade and Electronic Commerce: Behavioral Margins and the Design of International Tax Systems, December 2004

1367 Hans-Werner Sinn, EU Enlargement, Migration and the New Constitution, December 2004

1368 Josef Falkinger, Noncooperative Support of Public Norm Enforcement in Large Societies, December 2004 